\title{
MECHANISMS IN ENDOCRINOLOGY \\ New concepts to further unravel adrenal insufficiency during critical illness
}

\begin{abstract}
Eva Boonen and Greet Van den Berghe
Clinical Division and Laboratory of Intensive Care Medicine, Department of Cellular and Molecular Medicine, KU Leuven, Herestraat 49, B-3000 Leuven, Belgium
\end{abstract}

Correspondence should be addressed to E Boonen

Email

eva.boonen@

med.kuleuven.be

\section{Abstract}

The concept of 'relative' adrenal insufficiency during critical illness remains a highly debated disease entity. Several studies have addressed how to diagnose or treat this condition but have often yielded conflicting results, which further fuelled the controversy. The main reason for the controversy is the fact that the pathophysiology is not completely understood. Recently, new insights in the pathophysiology of the hypothalamic-pituitary-adrenal axis response to critical illness were generated. It was revealed that high circulating levels of cortisol during critical illness are explained more by reduced cortisol breakdown than by elevated cortisol production. Cortisol production rate during critical illness is less than doubled during the day but lower than in healthy subjects during the night. High plasma cortisol concentrations due to reduced breakdown in turn reduce plasma $A C T H$ concentrations via feedback inhibition, which with time may lead to an understimulation and hereby a dysfunction of the adrenal cortex. This could explain the high incidence of adrenal insufficiency in the prolonged phase of critical illness. These novel insights have created a new framework for the diagnosis and treatment of adrenal failure during critical illness that has redirected future research.

\section{Introduction}

Adrenal insufficiency acquired during critical illness was first described in 1946 by Hans Selye. Since then numerous studies aimed at further understanding this complex disease. Later, the distinction was made between 'absolute' and 'relative' adrenal insufficiency in the critically ill $(1,2,3)$. Absolute adrenal insufficiency as also diagnosed outside the intensive care unit (ICU) by endocrinologists is well characterised and understood and refers to a failing cortisol production. In contrast, relative adrenal insufficiency (RAI), a term that refers to a functional and likely transient deficiency acquired during critical illness and that implies an insufficiently activated adrenal cortex relative to the degree of stress, is a concept that is the subject of great controversy $(4,5,6)$. It is generally accepted that a pronounced and sustained activation of the hypothalamic-pituitary-adrenal (HPA) axis in

\section{Invited Author's profile}

Eva Boonen graduated in medicine in 2010 and is currently pursuing post doctoal research at the Department of Cellular and Molecular Medicine, KU Leuven, Leuven, Belgium. During her anesthesiology residency she started a doctoral thesis investigating HPA-axis alterations during critical illness, where she focused predominantly on cortisol metabolism. Her research revealed that cortisol metabolism is markedly reduced during critical illness and reshaped the current view on HPA-axis alterations with further implications for diagnois and treatment of adrenal insufficiency. As a post-doc reasearcher her main focus remains HPA-axis alterations during critical illness.

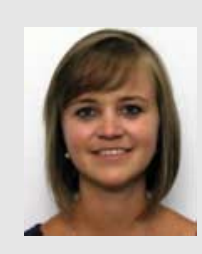

(C) 2016 European Society of Endocrinology Printed in Great Britain
Published by Bioscientifica Ltd. 
response to critical illness is vital. This is based largely on results of animal experiments revealing that adrenalectomy increases mortality of sepsis (7). However, the underlying mechanisms of RAI during critical illness are incompletely understood, contributing to the ongoing controversy as to whether such a state exists.

\section{The concept of adrenal insufficiency in critical illness}

\section{Absolute adrenal insufficiency in critical illness}

During critical illness, as well as outside the context of the ICU, absolute adrenal insufficiency has many possible causes $(1,2,3)$. Absolute adrenal insufficiency can be divided into primary, secondary and tertiary adrenal failure. Primary adrenal insufficiency is caused by diseases of the adrenal cortex. Adrenal dysfunction due to impaired adrenocorticotrophic hormone (ACTH) secretion because of pituitary abnormalities is labelled secondary adrenal insufficiency, while insufficient arginine-vasopressine or corticotrophinreleasing hormone $(\mathrm{CRH})$ secretion and function can cause tertiary adrenal insufficiency. The most common cause of tertiary adrenal insufficiency is long-term, high-dose glucocorticoid therapy, which suppresses the HPA axis by negative feedback inhibition $(1,2,3)$.

During critical illness, patients with a prior history of adrenal insufficiency are at the risk of developing an Addisonian crisis triggered by the stress of the disease. Besides the risk due to pre-existing adrenal insufficiency, new onset absolute adrenal failure can be evoked by critical illness itself. For example, adrenal insufficiency can be due to adrenal hemorrhage or adrenal vein thrombosis, for which ICU patients may be at higher risk given the coagulation disorders present in many types of severe illnesses. In addition, several medications frequently used in ICU can affect cortisol production. Etomidate is one of these drugs and is known to suppress cortisol production, even after a single dose. Other drugs known to influence the HPA axis are azoles, anticoagulants, phenobarbital, phenytoin, rifampin, opioids, chlorpromazine and imipramine (8).

Absolute adrenal insufficiency should be suspected whenever otherwise unexplained hypovolemia and/or catecholamine-resistant hypotension is present, especially when this occurs in a patient who also has hyperpigmentation, hyponatremia or hyperkalemia. A low plasma cortisol concentration with or without a low plasma ACTH concentration and a suppressed cortisol response to an ACTH stimulation test are further indicative of such a diagnosis of absolute adrenal insufficiency.
It is generally accepted that patients with an established diagnosis of primary or secondary adrenal failure or patients on chronic treatment with systemic glucocorticoids prior to critical illness should receive additional coverage with hydrocortisone to cope with the acute stress of the disease $(9,10)$. Also, patients who are diagnosed with an acute Addisonian crisis in the ICU are typically treated with high doses of glucocorticoids. This therapeutic strategy is based on the assumption that cortisol production during critical illness is several-fold increased as compared with during health. The conventional treatment proposes the administration of an i.v. bolus of $100 \mathrm{mg}$ of hydrocortisone followed by $50-100 \mathrm{mg}$ every $6 \mathrm{~h}$ on the first day, $50 \mathrm{mg}$ every $6 \mathrm{~h}$ on the second day and $25 \mathrm{mg}$ every $6 \mathrm{~h}$ on the third day, tapering to a maintenance dose by the fourth to fifth day $(9,10)$.

\section{RAl in critical illness}

When the degree of HPA-axis activation is assumed to be not enough to cover the need of cortisol to survive, even when plasma cortisol levels are still higher than during health, the condition has been labelled 'RAI' (4). More recently, the term 'critical illness-related corticosteroid insufficiency' (CIRCI) $(5,6)$ has been introduced, as such 'relative failure' during critical illness can occur at any level of the HPA axis and/or may be due to resistance to cortisol in the peripheral target tissues $(5,6)$. However, the possible underlying mechanisms remain highly debated. Pro-inflammatory cytokines have been suggested to induce target tissue resistance and to inhibit ACTH function $(2,11,12)$. Furthermore, impaired blood supply to the anterior pituitary gland can evoke ischemia or necrosis, accumulation of nitric oxide or central neuropeptides, and hereby decreased ACTH secretion (3). Additionally, several neuropeptides, oxidative stress, altered adrenal blood flow, cortisol precursor deficiency due to low circulating cholesterol levels or medications that suppress cortisol synthesis have also been suggested to play a role (8). Since cholesterol is produced in the liver, patients with liver diseases may have defective cholesterol production, which could increase the risk of adrenal insufficiency. Furthermore, the incidence of coagulopathy is higher in liver disease patients leading a higher risk of adrenal haemorrhage (13). Target tissue resistance to cortisol, the second part of the definition of CIRCI, refers to decreased glucocorticoid cellular uptake or suppressed expression or activation of the glucocorticoid receptor (GR). Low corticosteroid binding globulin (CBG) levels and decreased CBG affinity may impair cortisol transport. 
Furthermore, GR expression levels and affinity of the GR for cortisol can be altered by critical illness.

As for absolute adrenal insufficiency, initial diagnosis of suspected RAI starts with the clinical presentation. Hypotension refractory to fluid resuscitation and vasopressors may be signs of CIRCI, even when other symptoms of adrenal failure are absent. Suggested diagnostic criteria for CIRCI in critically ill patients have been based on one landmark study by Annane et al. (4) who identified a plasma cortisol incremental response $<9 \mu \mathrm{g} / \mathrm{dl}$ (for conversion of cortisol to SI units (nmol/l) multiply by 27.6) after the injection of $250 \mu \mathrm{g}$ ACTH (for conversion of ACTH to SI units (pmol/l) multiply by 0.22 ) in the face of a high baseline plasma cortisol concentration $(>34 \mu \mathrm{g} / \mathrm{dl})$ as most discriminative for an increased risk of death. However, these findings have not been replicated by other investigators, which explains why there is currently no consensus on the diagnostic criteria for RAI (5). Furthermore, also the dose of ACTH that should be used for the ACTH stimulation test remains controversial. A dose of $250 \mu \mathrm{g}$ of ACTH leads to supra-physiologic ACTH levels and could therefore overcome any ACTH resistance. Alternatively, a $1 \mu \mathrm{g}$ stimulation dose has been suggested but the diagnostic value hereof has not been extensively investigated in critically ill patients and the results of the studies have been conflicting $(14,15)$.

Other authors have suggested that the diagnosis of CIRCI can be made by a random total plasma cortisol concentration $<10 \mu \mathrm{g} / \mathrm{dl}$ during critical illness (5). However, total plasma cortisol concentration is derived from the result of adrenal production, secretion, distribution, binding and elimination of cortisol. Also, cortisol is secreted in a pulsatile manner (16). Overall, it thus seems impossible to assess the adrenal cortisol secretion rate with a single random cortisol measurement. Furthermore, total plasma cortisol concentrations give little information about glucocorticoid function. Only free cortisol can cross the cell membrane to exert its function by binding to the GR and consequently binding as a complex in the nucleus. The acute response to critical illness comprises an immediate fall in the circulating levels of the binding proteins, CBG and albumin, together with an altered CBGbinding affinity, which occurs via the cleavage of CBG at the sites of inflammation or in the circulation evoked by fever $(17,18,19,20,21)$. Plasma free cortisol has been suggested by other authors to be more appropriate than total plasma cortisol for the assessment of the HPA-axis functioning $(22,23)$. However, plasma free cortisol assays are currently not readily available and normal ranges of plasma free cortisol during critical illness have not been defined. Additionally, increasing evidence from both animal and human experiments suggests that GR availability in different tissues, the GR affinity and translocation are regulated during critical illness $(24,25,26,27,28,29)$. In septic patients, for example, the dominant negative $\beta$-isoform of the GR was induced from the onset of critical illness on, which downregulates glucocorticoid action (25). Given the impact of these changes on glucocorticoid function, they limit conclusions about 'adequacy' of cortisol availability during illness. Finally, a lack of accuracy and a high inter-assay variation in cortisol assays (30), further limits the use of on one cut-off value of cortisol in clinical practice to define CIRCI. It may be necessary to use mass spectrometry since this method is more accurate and less sensitive to confounders $(31,32)$.

The most recent guidelines for the treatment of sepsis no longer recommend to use the ACTH stimulation test for the diagnosis of CIRCI (33). Instead, the guidelines suggest to use a random cortisol level $<18 \mu \mathrm{g} / \mathrm{dl}$ in a patient with septic shock and clinical suspicion of adrenal failure as an indication for initiation of steroid therapy (33). These current recommendations are still largely based on expert opinion.

Other experts have recently suggested to measure interstitial cortisol levels in critically ill patients to assess the amount of cortisol availability for target tissues $(34,35)$. To this end, a microdialysis catheter is inserted into the subcutaneous adipose tissue. However, edema is frequently present in the critically ill, regional blood flow is variable and it is unclear what the subcutaneous adipose tissue tells the clinician about the other target tissues of interest in the critically ill (36). The usefulness of this invasive technique thus remains unclear.

Perhaps even more controversial than the diagnostic criteria is the issue of when treatment of CIRCI with exogenous glucocorticoids is required and which doses should be used. This controversy is mainly fuelled by the conflicting results of two large randomised controlled trials (RCT). The first large trial by Annane et al. (37) investigated 300 patients with septic shock on vasopressor therapy. All patients received an ACTH stimulation test and were randomly assigned to be treated with placebo or with $200 \mathrm{mg}$ hydrocortisone plus $50 \mu \mathrm{g}$ fludrocortisone/ day for 7 days. The study showed that glucocorticoid treatment reduced the duration of vasopressor therapy. There was no overall benefit on survival, but in the subgroup of patients who showed a low cortisol incremental response to the ACTH stimulation test, the treatment reduced 28 days mortality by an absolute $10 \%$. However, the relevance of this subgroup analysis has been 
questioned as well as the bias induced by widespread use of etomidate during this study. The repeat RCT also could not confirm this beneficial effect on survival of a treatment with hydrocortisone for septic shock. Indeed, this multicenter randomised-controlled double-blind trial included 499 patients and investigated the impact on 28 days mortality of $200 \mathrm{mg}$ hydrocortisone daily or placebo for 5 days after which a tapering period followed (38). This study revealed that hydrocortisone treatment increased blood pressure but did not improve survival, neither in the non-responders to ACTH stimulation, nor in the entire population. Moreover, an increased incidence of septic shock relapse was observed. However this study was also criticised, mainly for its early stop due to slow patient recruitment, which reduced the statistical power of the trial.

A systematic review of all high-quality RCTs recently concluded that hydrocortisone therapy does not reduce mortality of severe sepsis (39). Recent guidelines now recommend, although with a weak level of confidence, to only treat patients with hypotension refractory to vasopressor or fluid resuscitation. A dose of $200 \mathrm{mg}$ hydrocortisone via continuous infusion is advised, with a quick tapering down of the dose whenever vasopressors are no longer needed. The guidelines do not advise glucocorticoid treatment for patients with sepsis without shock (33).

\section{Better understanding the HPA-axis regulation during critical illness?}

Further optimization of diagnosis and treatment of critical illness-induced adrenal insufficiency clearly requires a better understanding of the HPA-axis pathophysiology in this context. The stress response is considered to start at the level of the hypothalamus, with the release of CRH into the portal circulation, which stimulates the pituitary corticotrophs to secrete ACTH, in turn activating the production and release of cortisol in the adrenal cortex. Negative feedback inhibition by cortisol at the level of CRH and ACTH can turn off this activation of the HPA-axis to regain homeostasis. Critical illness is considered to be a condition of severe physical stress and the typically high plasma free and total cortisol concentrations are assumed to be explained by such a stress-induced HPA-axis activation with several-fold increased cortisol production. However, an observation which does not support such an HPA-axis activation during critical illness is the low plasma ACTH. Vermes et al. (40) showed that plasma ACTH concentrations in patients suffering from severe trauma or sepsis were only transiently elevated and after a few days dropped below those observed in healthy control subjects in the face of high plasma cortisol. Furthermore, in a more heterogeneous long-stay ICU patient population, plasma ACTH concentrations were found to be suppressed from day 1 in ICU throughout the first week of critical illness, again in the presence of high plasma cortisol (41).

This dissociation between ACTH and cortisol suggested that non-ACTH-mediated mechanisms regulate cortisol availability during critical illness. Theoretically, an increased sensitivity for ACTH might explain low ACTH and concomitantly high cortisol. However, since the incremental cortisol response to an ACTH stimulation test during critical illness is never increased and often low, this appears unlikely (4). The possible role of other nonACTH stimulators of cortisol production in the adrenal cortex has often been suggested (12). Animal and cell culture studies investigated the role of cytokines, neuropeptides and other mediators of such an increased cortisol production. However, since cortisol production had not been quantified in the context of modern intensive care until recently, the long-standing assumption of a severalfold increased cortisol production during critical illness was based only on extrapolation from the increased circulating (free) cortisol levels. Recently cortisol production was quantified during critical illness with the use of the gold standard deuterated cortisol tracer technique (41). This study showed that daytime cortisol production during critical illness was only twice that of healthy subjects, but found that cortisol breakdown was substantially reduced which resulted in a fivefold longer half-life of cortisol, which explained the high plasma cortisol levels (Fig. 1). The reduced cortisol breakdown was explained by suppressed expression and activity of A-ring reductases in the liver and by suppressed activity 11ß-hydroxysteroid dehydrogenase type 2 in kidney (41). A subsequent study that used deconvolution analysis, taking the fivefold longer cortisol half-life into account, showed that nocturnal cortisol secretion was actually lower than in healthy subjects (42). Hence, the 24-h cortisol production rate in many critically ill patients with high plasma cortisol levels may not be much higher compared with the healthy controls.

In this concept, the low plasma ACTH concentrations may well be explained by negative feedback inhibition exerted by elevated plasma cortisol brought about by reduced cortisol breakdown. If ACTH levels remain suppressed for an extended period of time, this could have adverse consequences for the integrity of the adrenal cortex, which would be relevant predominantly in the prolonged phase of illness. A study of adrenal cortex 

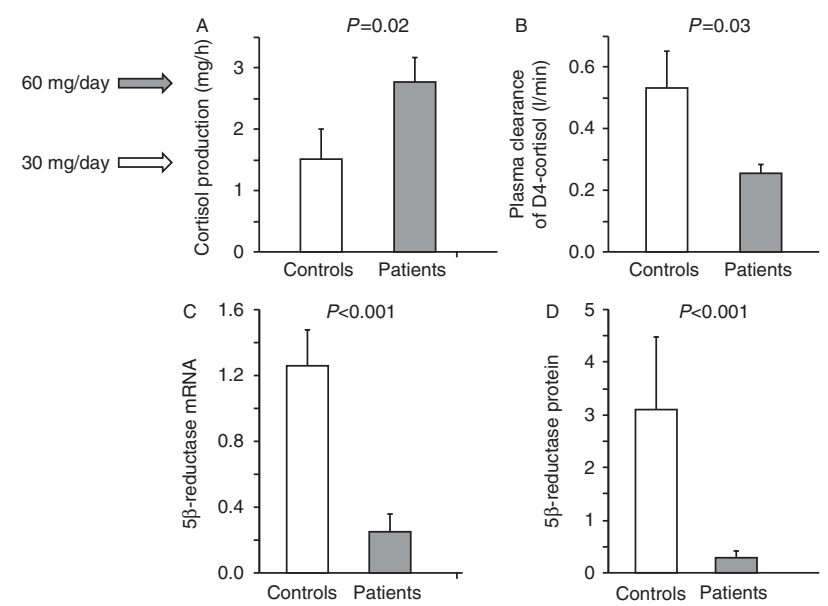

\section{Figure 1}

(A) represents cortisol production in critically ill patients ( $n=11$, grey bar) compared with the controls ( $n=9$, white bar). (B) represents cortisol plasma clearance after a small dose of deuterated-cortisol tracer. Bar charts represent means and standard errors. Based on these results, 24-h cortisol production was estimated and depicted with the arrows. (C) and (D) show mRNA and protein expression of $5 \beta$-reductase in liver of 20 controls (white bar) and 44 patients (grey bar). Bar charts represent means and standard errors. The mRNA data are expressed, normalised to GAPDH, as a fold difference from the mean of the controls. Protein data are expressed normalised for CK-18 protein expression, as a fold difference from the mean of the controls. Figure reproduced from Boonen $E$, Vervenne $H$, Meersseman P, Andrew R, Mortier L, Declercq PE, Vanwijngaerden YM, Spriet I, Wouters PJ \& Vander Perre S. Reduced cortisol metabolism during critical illness. New England Journal of Medicine 201318 1477-1488. Copyright ( () (2013) Massachusetts Medical Society. Reprinted with permission.

biopsies harvested post-mortem from acute and prolonged (7 days or more) critically ill patients and from sudden out of hospital deaths showed a very pronounced depletion of cholesterol esters and suppressed expression of ACTH-regulated genes in adrenal glands from prolonged, but not acute, critically ill patients (43). Unfortunately, given the nature of the study, blood samples were not available to correlate the observed changes with plasma ACTH and cortisol concentrations. However, these results are strikingly reminiscent of the phenotype of pro-opiomelanocortin-deficient mice, which suggests that a sustained lack of ACTH-effect on the adrenal cortex may indeed explain these findings (44). These changes in the adrenal cortex of prolonged ICU stay-patients also help to explain the reported 20-fold higher incidence of symptomatic adrenal insufficiency in critically ill patients being treated in the ICU for more than 14 days (45).

\section{A new context in which to reconsider diagnosis and treatment of adrenal insufficiency during critical illness?}

The recent novel insights have reshaped the understanding of the HPA-axis regulation during critical illness, but have also provided a new context in which to reconsider diagnosis and treatment of adrenal insufficiency in that setting.

First, if a primary adrenal failure would be the reason for an insufficiently increased cortisol production and thus insufficiently increased plasma cortisol concentrations, one would expect a high plasma ACTH concentration, which has not been reported $(40,41)$. Secondly, it was shown that the cortisol incremental cortisol response to an ACTH stimulation test in critically ill patients correlated positively with both cortisol production rate and cortisol plasma clearance (41) (Fig. 2). Patients who revealed a low cortisol response to ACTH, below the threshold of absolute adrenal failure (46) were the ones who also had the most reduced cortisol breakdown, whereas their cortisol production rate was still comparable with that of the healthy subjects. This small piece of evidence could suggest that a low incremental cortisol response to an ACTH injection give little information about the adequacy of cortisol production but may reflect the degree of reduced cortisol metabolism leading to increased cortisol levels that exert a certain degree off negative feedback. This would be comparable with what is observed in patients and who are treated with exogenous glucocorticoids for an extended time, as they also reveal a suppressed cortisol response to ACTH injection, in the face of very high levels of (exogenous) glucocorticoids (47). Thirdly, the response to an ACTH stimulation test is poorly reproducible in critically ill patients (48) and increasing evidence supports the hypothesis that adrenal function during critical illness is dynamic. Therefore, perhaps the use of repetitive measurements of plasma cortisol over time together with repetitive ACTH stimulation tests could shed more light on the nature of adrenocortical dysfunction in critically ill patients. It has already been suggested that the cortisol responsiveness to ACTH restores after recovery of illness, while a decreasing cortisol response during repetitive ACTH-testing was associated with a poor prognosis $(23,49,50)$. Unfortunately, large enough and well-designed prospective clinical studies of systematic ACTH stimulation tests 

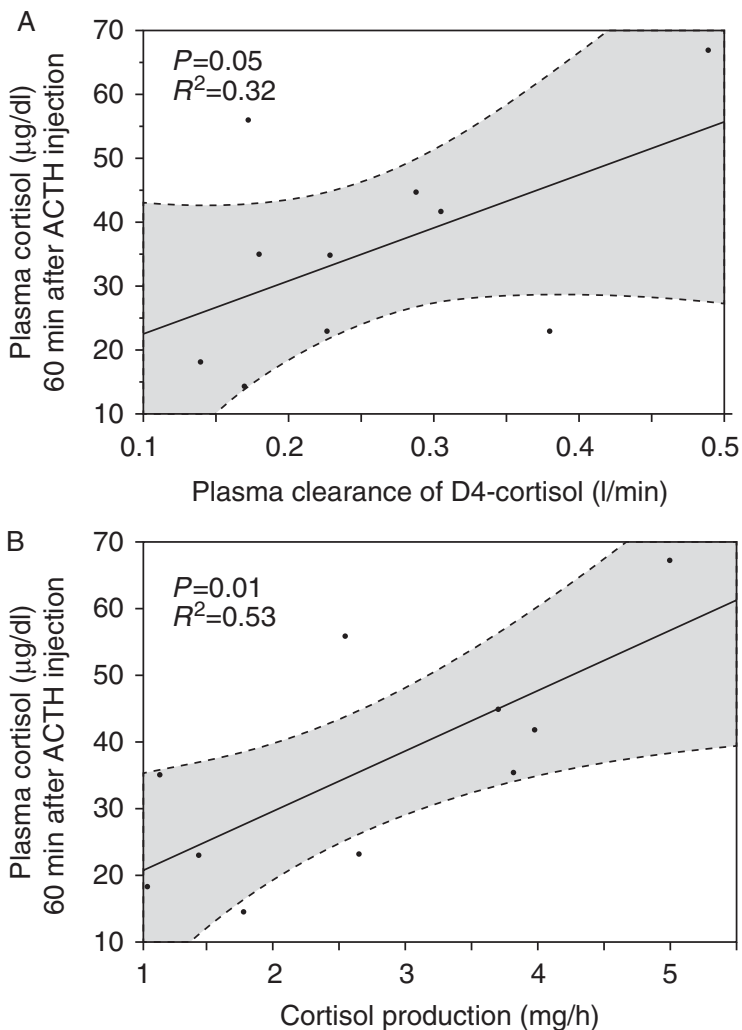

\section{Figure 2}

(A) shows the correlation between plasma clearance of D4-cortisol with plasma cortisol responses, 60 min after ACTH injection $(250 \mu \mathrm{g})$ among patients $(n=10)$. (B) shows the correlation between cortisol production with plasma cortisol responses, 60 min after ACTH injection $(250 \mu \mathrm{g})$ among patients $(n=10)$. The shaded area represents $95 \% \mathrm{Cl}$. Figure reproduced from Boonen E, Vervenne H, Meersseman P, Andrew R, Mortier L, Declercq PE, Vanwijngaerden Y-M, Spriet I, Wouters PJ \& Vander Perre S et al. Reduced cortisol metabolism during critical illness. New England Journal of Medicine 201318 1477-1488. (doi:10.1056/NEJMoa1214969) Copyright (๑) (2013) Massachusetts Medical Society. Reprinted with permission.

performed on repeated time points into the prolonged phase of critical illness and recovery are currently lacking.

The use of repetitive cortisol measurements may be additionally important, taking into account the limitations of a single total or free cortisol measurement. If persistently low circulating ACTH levels lead to the downregulation of ACTH signalling in the adrenal cortex (43), this could compromise adrenal function and preclude any additional cortisol to be produced whenever a next problem occurs during prolonged critical illness. This would be reflected in a progressively lower plasma cortisol concentrations with time, coinciding with a lowering of the incremental cortisol response to an ACTH test. Such a time course was already suggested by a recent small study that showed that plasma cortisol levels decreased in the prolonged phase of illness (51).

Also the time course of repetitive quantification of plasma ACTH, concomitantly measured with repetitive plasma cortisol and integrated with the results of repetitive ACTH tests, could be quite informative. Indeed, if sustained negative feedback inhibition by high cortisol that is not broken down play a role in the suppression of plasma ACTH during sustained critical illness, one could expect that plasma ACTH levels rise as soon as cortisol breakdown increases again with recovery. On the other hand when the ACTH levels remain low, the coinciding effect on the adrenal cortex would limit sufficient cortisol availability in the prolonged critically ill due to decreased cortisol production and may indicate who would benefit from treatment with hydrocortisone (Fig. 3).

Recent insights indeed stress the importance of correctly identifying patients with a truly failing adrenal cortex for treatment. A recent animal study showed that corticosteroid treatment is only beneficial in septic mice with an absolute adrenal insufficiency, while it harmed the mice without such adrenal insufficiency (52). Besides the importance of accurately determining 'who' to treat, it also should be further investigated 'how' to best treat these patients. The currently proposed dose of $200 \mathrm{mg}$ of hydrocortisone/day, referred to as 'low dose' in the literature, is in fact between three- and sixfold higher than the cortisol production rate that was recently quantified in critically ill patients (41). Furthermore, given the fivefold longer cortisol half-life in critically ill patients than in healthy control subjects, the hydrocortisone doses of $200 \mathrm{mg} /$ day will expectedly result in high circulating (and possibly also tissue) cortisol levels during critical illness, with risks of side effects (41). Reducing cortisol breakdown may also be a clever mechanism during illness to regulate cortisol availability in a tissue-specific manner, directing high availability to those organs that express the cortisol metabolizing enzymes such as liver and kidney, while this could prevent too high levels of cortisol in those tissues that are susceptible to excessive glucocorticoid exposure such as skeletal muscle. Treatment with exogenous glucocorticoids in too high doses expectedly will increase cortisol availability in all tissues explaining the potentially deleterious effects of this treatment $(53,54)$. In fact, the novel finding of an increased cortisol half-life during critical illness not only affects the decision on who and how to treat for adrenal failure, but should also be 


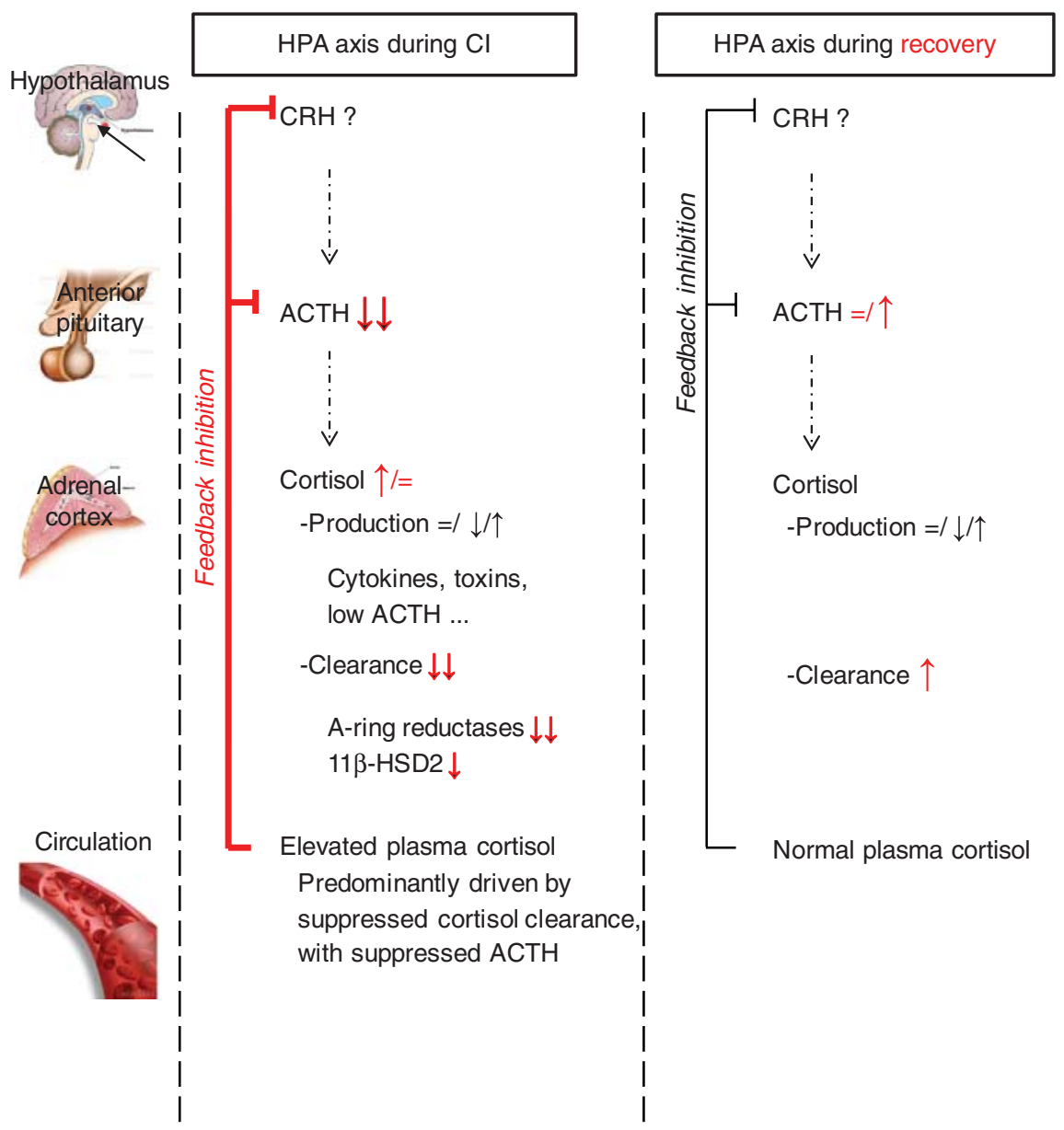

HPA axis during sustained $\mathrm{Cl}$

$\mathrm{CRH} ?$

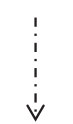

$\mathrm{ACTH} \downarrow \downarrow$

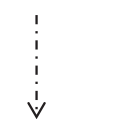

Cortisol

-Production $\downarrow \downarrow$ due to adrenal failure

-Clearance $\downarrow \downarrow$

Risk of

low plasma cortisol

Figure 3

Schematic overview of the HPA-axis regulation during critical illness, recovery or sustained critical illness.

taken into account for treatment of ICU-patients with steroids for other indications. It is clear that more research is urgently needed to clarify the diagnostic and therapeutic implications of the novel pathophysiological insights.

\section{Can preliminary recommendations be made?}

While we eagerly await well-designed clinical studies to provide more evidence on how to better diagnose and treat critically ill patients with adrenal failure, perhaps some empirical recommendations can be made. During the acute phase of illness, there is little or no evidence to support the presence of 'relative adrenal failure' requiring treatment. Long-stay patients with symptoms consistent with adrenal failure and decreasing random plasma cortisol together with a progressively lowering of the cortisol response to repetitive ACTH stimulation tests could be at risk of suffering from critical illness-induced adrenal failure.
The experimental guideline applied at the authors' institution identifies patients at risk of having adrenal failure eligible for treatment by the following rule of thumb: critically ill patients with symptoms (unexplained vasoplegia and/or coma for example) who are in the ICU for more than 6 days, with progressively decreasing plasma baseline cortisol concentrations that fall below $6 \mu \mathrm{g} / \mathrm{dl}$ and with an incremental cortisol response to an ACTH stimulation test ( $250 \mu \mathrm{g}$ i.v. bolus) of $<6 \mu \mathrm{g} / \mathrm{dl}$. Evidently, these specific threshold levels only apply to the institution's assay (RIA from Immunotech, Prague, Czech Republic) and cannot be extrapolated to other assays without comparative validation studies.

Regarding treatment, historical doses of $200 \mathrm{mg}$ hydrocortisone/day are likely too high given the substantially increased cortisol half-life during critical illness. Based on the stable isotope studies (39) it appears that a dose of $\sim 60 \mathrm{mg}$ of hydrocortisone, as extrapolated from 
the tracer study, may be interesting to investigate in future studies. A tapering down to the lowest effective dose as soon as possible should be advised to limit any adverse effects of excessive amounts of glucocorticoids during critical illness.

\section{Declaration of interest}

The authors declare that there is no conflict of interest that could be perceived as prejudicing the impartiality of the review.

\section{Funding}

The work summarised in this review has been supported by research grants from the Fund for Scientific Research Flanders Belgium (GVdB), by the Methusalem Program funded by the Flemish Government (GVdB) and by the European Research Council under the European Union's Seventh Framework Program (FP7/2007-2013 ERC Advanced Grant Agreement no. 307523) (GVdB).

\section{References}

1 Arlt W. The approach to the adult with newly diagnosed adrenal insufficiency. Journal of Clinical Endocrinology and Metabolism 200994 1059-1067. (doi:10.1210/jc.2009-0032)

2 Charmandari E, Nicolaides NC \& Chrousos GP. Adrenal insufficiency. Lancet 201421 2152-2167. (doi:10.1016/S0140-6736(13)61684-0)

3 Oelkers W. Adrenal insufficiency. New England Journal of Medicine 1996 335 1206-1212. (doi:10.1056/NEJM199610173351607)

4 Annane D, Sebille V, Troche G, Raphael JC, Gajdos P \& Bellissant E. A 3-level prognostic classification in septic shock based on cortisol levels and cortisol response to corticotropin. Journal of the American Medical Association 2000283 1038-1045. (doi:10.1001/jama.283.8. 1038)

5 Marik PE, Pastores SM, Annane D, Meduri GU, Sprung CL, Arlt W, Keh D, Briegel J, Beishuizen A, Dimopoulou I et al. Recommendations for the diagnosis and management of corticosteroid insufficiency in critically ill adult patients: consensus statements from an international task force by the American College of Critical Care Medicine. Critical Care Medicine 200836 1937-1949. (doi:10.1097/CCM. Ob013e31817603ba)

6 Marik PE. Critical illness-related corticosteroid insufficiency. Chest 2009 135 181-193. (doi:10.1378/chest.08-1149)

7 Bertini R, Bianchi M \& Ghezzi P. Adrenalectomy sensitizes mice to the lethal effects of interleukin 1 and tumor necrosis factor. Journal of Experimental Medicine 1988167 1708-1712. (doi:10.1084/jem.167.5. 1708)

8 Bornstein SR. Predisposing factors for adrenal insufficiency. New England Journal of Medicine 2009360 2328-2339. (doi:10.1056/ NEJMra0804635)

9 Chung TT, Grossman A \& Clark AJL. Adrenal insufficiency. In Endocrinology Adult and Pedicatric, 6th edn, ch 6, pp 1853-1863. Eds JL Jameson \& LJ De Groot. St Louis MO: WB Saunders, 2010.

10 Debaveye Y, Vandenbrande J \& Van den Berghe G. Endocrine emergencies. In The ESC Textbook of Intensive and Acute Cardiac Care, 1st Edition, ch 68, pp 709-717. Eds M Tubaro, N Danchin, G Filippatos \& P Goldstein. Oxford: Oxford University Press, 2011.

11 Silverman MN \& Sternberg EM. Glucocorticoid regulation of inflammation and its functional correlates: from HPA axis to glucocorticoid receptor dysfunction. Annals of the New York Academy of Sciences 20121261 55-63. (doi:10.1111/j.1749-6632.2012.06633.x)
12 Bornstein SR, Engeland WC, Ehrhart-Bornstein M \& Herman JP. Dissociation of ACTH and glucocorticoids. Trends in Endocrinology and Metabolism 200819 175-180. (doi:10.1016/j.tem.2008.01.009)

13 Tsai MH, Peng YS, Chen YC, Liu NJ, Ho YP, Fang JT, Lien JM, Yang C, Chen PC \& Wu CS. Adrenal insufficiency in patients with cirrhosis, severe sepsis and septic shock. Hepatology 200643 673-681. (doi:10.1002/hep.21101)

14 Moraes RB, Friedman G, Tonietto T, Saltz H \& Czepielewski M. Comparison of low and high dose cosyntropin stimulation tests in the diagnosis of adrenal insufficiency in septic shock patients. Hormone and Metabolic Research 201244 296-301. (doi:10.1055/s-0032-1304320)

15 Kozyra EF, Wax RS \& Burry LD. Can 1 microg of cosyntropin be used to evaluate adrenal insufficiency in critically ill patients? Annals of Pharmacotherapy 200539 691-698. (doi:10.1345/aph.1E139)

16 Gibbison B, Angelini GD \& Lightman SL. Dynamic output and control of the hypothalamic-pituitary-adrenal axis in critical illness and major surgery. British Journal of Anaesthesia 2013111 347-360. (doi:10.1093/bja/aet077)

17 Hamrahian AH, Oseni TS \& Arafah BM. Measurements of serum free cortisol in critically ill patients. New England Journal of Medicine 2004 350 1629-1638. (doi:10.1056/NEJMoa020266)

18 Cameron A, Henley D, Carrell R, Zhou A, Clarke A \& Lightman S. Temperature-responsive release of cortisol from its binding globulin: a protein thermocouple. Journal of Clinical Endocrinology and Metabolism 201095 4689-4695. (doi:10.1210/jc.2010-0942)

19 Chan WL, Carrell RW, Zhou A \& Read RJ. How changes in affinity of corticosteroid-binding globulin modulate free cortisol concentration. Journal of Clinical Endocrinology and Metabolism 201398 3315-3322. (doi:10.1210/jc.2012-4280)

20 Holland PC, Hancock SW, Hodge D, Thompson D, Shires S \& Evans S. Degradation of albumin in meningococcal sepsis. Lancet $2001 \mathbf{3 5 7}$ 2102-2104. (doi:10.1016/S0140-6736(00)05200-4)

21 Pugeat M, Bonneton A, Perrot D, Rocle-Nicolas B, Lejeune H, Grenot C, Déchaud H, Brébant C, Motin J \& Cuilleron CY. Decreased immunoreactivity and binding activity of corticosteroid-binding globulin in serum in septic shock. Clinical Chemistry 198935 1675-1679.

22 Molenaar N, Johan Groeneveld AB, Dijstelbloem HM, de Jong MF, Girbes AR, Heijboer AC \& Beishuizen A. Assessing adrenal insufficiency of corticosteroid secretion using free versus total cortisol levels in critical illness. Intensive Care Medicine 201137 1986-1993. (doi:10.1007/s00134-011-2342-x)

23 Ho JT, Al-Musalhi H, Chapman MJ, Quach T, Thomas PD, Bagley CJ, Lewis JG \& Torpy DJ. Septic shock and sepsis: a comparison of total and free plasma cortisol levels. Journal of Clinical Endocrinology and Metabolism 200691 105-114. (doi:10.1210/jc.2005-0265)

24 Bergquist M, Nurkkala M, Rylander C, Kristiansson E, Hedenstierna G \& Lindholm C. Expression of the glucocorticoid receptor is decreased in experimental Staphylococcus aureus sepsis. Journal of Infection $2013 \mathbf{6 7}$ 574-583. (doi:10.1016/j.jinf.2013.07.028)

25 Guerrero J, Gatica HA, Rodriguez M, Estay R \& Goecke IA. Septic serum induces glucocorticoid resistance and modifies the expression of glucocorticoid isoforms receptors: a prospective cohort study and in vitro experimental assay. Critical Care 201317 R107. (doi:10.1186/cc12774)

26 Indyk JA, Candido-Vitto C, Wolf IM, Venkataraman S, Munoz R, Saladino RA, Witchel SF \& Defranco DB. Reduced glucocorticoid receptor protein expression in children with critical illness. Hormone Research in Paediatrics 201379 169-178. (doi:10.1159/000348290)

27 Peeters RP, Hagendorf A, Vanhorebeek I, Visser TJ, Klootwijk W, Mesotten D, Wouters PJ, Koper JW, de Jong FH, Feelders RA et al. Tissue mRNA expression of the glucocorticoid receptor and its splice variants in fatal critical illness. Clinical Endocrinology 200971 145-153. (doi:10.1111/j.1365-2265.2008.03443.x)

28 Siebig S, Meinel A, Rogler G, Klebl E, Wrede CE, Gelbmann C, Froh S, Rockmann F, Bruennler T, Schoelmerich J et al. Decreased cytosolic glucocorticoid receptor levels in critically ill patients. Anaesthesia and Intensive Care 201038 133-140. 
29 van den Akker EL, Koper JW, Joosten K, de Jong FH, Hazelzet JA, Lamberts SW \& Hokken-Koelega AC. Glucocorticoid receptor mRNA levels are selectively decreased in neutrophils of children with sepsis. Intensive Care Medicine 200935 1247-1254. (doi:10.1007/s00134-0091468-6)

30 Cohen J, Ward G, Prins J, Jones M \& Venkatesh B. Variability of cortisol assays can confound the diagnosis of adrenal insufficiency in the critically ill population. Intensive Care Medicine 200632 1901-1905. (doi:10.1007/s00134-006-0389-x)

31 Stenman UH. Standardization of hormone determinations. Best Practice Research Clinical Endocrinology Metabolism 201327 823-830. (doi:10.1016/j.beem.2013.10.007)

32 Keevil BG. Novel liquid chromatography tandem mass spectrometry (LC-MS/MS) methods for measuring steroids. Best Practice Research Clinical Endocrinology Metabolism 201327 663-674. (doi:10.1016/j. beem.2013.05.015)

33 Dellinger RP, Levy MM, Rhodes A, Annane D, Gerlach H, Opal SM, Sevransky JE, Sprung CL, Douglas IS, Jaeschke R et al. Surviving sepsis campaign: international guidelines for management of severe sepsis and septic shock: 2012. Critical Care Medicine 201341 580-637. (doi:10.1097/CCM.0b013e31827e83af)

34 Vassiliadi DA, Ilias I, Tzanela M, Nikitas N, Theodorakopoulou M, Kopterides P, Maniatis N, Diamantakis A, Orfanos SE, Perogamvros I et al. Interstitial cortisol obtained by microdialysis in mechanically ventilated septic patients: correlations with total and free serum cortisol. Journal of Critical Care 201328 158-165. (doi:10.1016/j.jcrc. 2012.07.008)

35 Venkatesh B, Morgan TJ \& Cohen J. Interstitium: the next diagnostic and therapeutic platform in critical illness. Critical Care Medicine 2010 38 S630-S636. (doi:10.1097/CCM.0b013e3181f24406)

36 Trzeciak S, Dellinger RP, Parrillo JE, Guglielmi M, Bajaj J, Abate NL, Arnold RC, Colilla S, Zanotti S \& Hollenberg SM. Early microcirculatory perfusion derangements in patients with severe sepsis and septic shock: relationship to hemodynamics, oxygen transport, and survival. Annals of Emergency Medicine 200749 88-98. (doi:10.1016/j.annemergmed. 2006.08.021)

37 Annane D, Sébille V, Charpentier C, Bollaert PE, François B, Korach JM, Capellier G, Cohen Y, Azoulay E, Troché G et al. Effect of treatment with low doses of hydrocortisone and fludrocortisone on mortality in patients with septic shock. Journal of the American Medical Association 2002288 862-871. (doi:10.1001/jama.288.7.862)

38 Sprung CL, Annane D, Keh D, Moreno R, Singer M, Freivogel K, Weiss YG, Benbenishty J, Kalenka A, Forst $\mathrm{H}$ et al. Hydrocortisone therapy for patients with septic shock. New England Journal of Medicine 2008358 111-124. (doi:10.1056/NEJMoa071366)

39 Patel GP \& Balk RA. Systemic steroids in severe sepsis and septic shock. Americal Journal of Respiratory Critical Care Medicine 201215 133-139. (doi:10.1164/rccm.201011-1897CI)

40 Vermes I, Beishuizen A, Hampsink RM \& Haanen C. Dissociation of plasma adrenoACTH and cortisol levels in critically ill patients: possible role of endothelin and atrial natriuretic hormone. Journal of Clinical Endocrinology and Metabolism 199580 1238-1242. (doi:10.1210/jcem. 80.4.7714094)

41 Boonen E, Vervenne H, Meersseman P, Andrew R, Mortier L, Declercq PE, Vanwijngaerden Y-M, Spriet I, Wouters PJ, Vander Perre S et al. Reduced cortisol metabolism during critical illness. New England
Journal of Medicine 2013368 1477-1488. (doi:10.1056/ NEJMoa1214969)

42 Boonen E, Meersseman P, Vervenne H, Meyfroidt G, Guïza F, Wouters PJ, Veldhuis JD \& Van den Berghe G. Reduced nocturnal ACTH-driven cortisol secretion during critical illness. American Journal of Physiology Endocrinology and Metabolism 2014306 E883-E892. (doi:10.1152/ ajpendo.00009.2014)

43 Boonen E, Langouche L, Janssens T, Meersseman P, Vervenne H, De Samblanx E, Pironet Z, Van Dijck L, Vander Perre S, Derese I et al. Impact of duration of critical illness on the adrenal glands of human intensive care patients. Journal of Clinical Endocrinology and Metabolism 201499 4214-4222. (doi:10.1210/jc.2014-2429)

44 Karpac J, Czyzewska K, Kern A, Brush RS, Anderson RE \& Hochgeschwender U. Failure of adrenal corticosterone production in POMC-deficient mice results from lack of integrated effects of POMC peptides on multiple factors. American Journal of Physiology, Endocrinology and Metabolism 2008295 E446-E455. (doi:10.1152/ ajpendo.00762.2007)

45 Barquist E \& Kirton O. Adrenal insufficiency in the surgical intensive care unit patient. Journal of Trauma 199742 27-31. (doi:10.1097/ 00005373-199701000-00006)

46 Trainer PJ \& Besser M. The Bart's Endocrine Protocols, 1st Edition, ch 1, p 52. Eds M Parkinson, D Jones \& S Hunter. New York: Churchill Livingstone, 1995.

47 Sacre K, Dehoux M, Chauveheid MP, Chauchard M, Lidove O, Roussel R $\&$ Papo T. Pituitary-adrenal function after prolonged glucocorticoid therapy for systemic inflammatory disorders: an observational study. Journal of Clinical Endocrinology and Metabolism 201398 3199-3205. (doi:10.1210/jc.2013-1394)

48 Loisa P, Uusaro A \& Ruokonen E. A single adrenocorticotropic hormone stimulation test does not reveal adrenal insufficiency in septic shock. Anesthesia \& Analgesia 2005101 1792-1798. (doi:10.1213/01.ANE. 0000184042.91452.48)

49 Briegel J, Schelling G, Haller M, Mraz W, Forst H \& Peter K. A comparison of the adrenocortical response during septic shock and after complete recovery. Intensive Care Medicine 199622 894-899. (doi:10.1007/BF02044113)

50 de Jong MF, Beishuizen A, van Schijndel RJ, Girbes AR \& Groeneveld AB. Risk factors and outcome of changes in adrenal response to ACTH in the course of critical illness. Journal of Intensive Care Medicine 201227 37-44. (doi:10.1177/0885066610393456)

$51 \mathrm{Wu}$ JY, Hsu SC, Ku SC, Ho CC, Yu CJ \& Yang PC. Adrenal insufficiency in prolonged critical illness. Critical Care 200812 R65. (doi:10.1186/ cc6895)

52 Ai J, Guo L, Zheng Z, Wang SX, Huang B \& Li XA. Corticosteroid therapy benefits septic mice with adrenal insufficiency but harms septic mice without adrenal insufficiency. Critical Care Medicine 201543 e490-e498. (doi:10.1097/CCM.0000000000001264)

53 Hermans G, Wilmer A, Meersseman W, Milants I, Wouters PJ, Bobbaers H, Bruyninckx F \& Van den Berghe G. Impact of intensive insulin therapy on neuromuscular complications and ventilator dependency in the medical intensive care unit. Americal Journal of Respiratory Critical Care Medicine 2007175 480-489. (doi:10.1164/rccm. 200605-665OC)

54 Hermans G, De Jonghe B, Bruyninckx F \& Van den Berghe G. Clinical review: critical illness polyneuropathy and myopathy. Critical Care 200812 238. (doi:10.1186/cc7100)

Received 7 November 2015

Revised version received 15 January 2016

Accepted 25 January 2016 